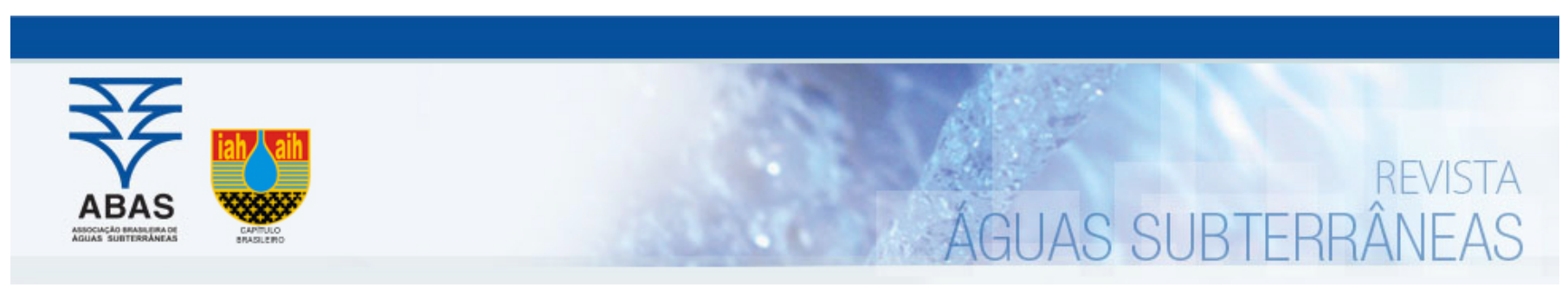

Artigos

\title{
Correlação entre dados de perfilagem geofísica e potencial de bombeamento de poços em litotipos da Formação Cauê no sudoeste do Quadrilátero Ferrífero, MG
}

\author{
Correlation between geophysical data and pumping potencial in deep wells \\ located in the Cauê Formation, southwestern portion of the Quadrilatero \\ Ferrifero, MG
}

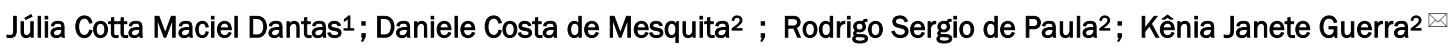 \\ 1 Universidade Federal de Ouro Preto (UFOP), Ouro Preto, MG, Brasil. \\ 2 CSN Mineração S.A., Congonhas, MG, Brasil.
}

\cmd.julia@gmail.com; dani.mesquit@gmail.com ; rodrigo.spdm@yahoo.com.br ; geokenia@hotmail.com

\begin{abstract}
Resumo
O presente artigo consiste em uma integração litológica-hidrológica com base em dados de perfilagem geofísica realizada em poços tubulares profundos. Seu principal objetivo é a comparação e definição dos litotipos mais favoráveis para prospecção de água subterrânea na área de estudo. A metodologia envolveu a análise dos perfis geofísicos e sua interpretação em conjunto com a litologia e valores de vazão específica de cada poço. No caso dos litotipos do Aquífero Cauê, as litologias brandas tendem a ter mais água que litologias compactas e, de modo geral, hematitas são mais ricas em água do que itabiritos, ainda que, a quantidade de água nos diferentes tipos de itabirito tenha uma boa variação.
\end{abstract}

Palavras-chave:

Aquífero Cauê.

Perfilagem geofísica.

Hidrogeologia.

\section{Abstract}

This article deals with a lithological-hydrological integration based on geophysical logging in deep wells. Its objective is to compare and define the most favorable lithotypes to groundwater prospection in the studied area. The methodology comprised well logging analysis together with the lithology and specific flow rate of each well. In the Cauê aquifer, the soft lithologies are more propense to have water than compact lithotypes. Furthermore, hematite is richer in water than itabirite, although the water quantity varies in different kinds of itabirite.

DOI: http://dx.doi.org/10.14295/ras.v31i4.28910

\section{INTRODUÇÃO}

Por constituir uma das maiores províncias minerais do Brasil e abrigar importantes minas de ouro e de minério de ferro, o Quadrilátero Ferrífero (QF) é alvo de estudos geológicos tanto pela sua complexidade estrutural e tectônica quanto por sua importância econômica. Dentre outros, citam-se os trabalhos de Rosière (1981), Chemale Jr. et al. (1987), Rosière (1992), Zavaglia (1995), Rosière et al. (1995), Endo (1997), Alkmim \& Marshak (1998) e Zucchetti \& Baltazar (2000).

A Formação Cauê, onde estão as formações ferríferas é, entretanto, um dos melhores aquíferos da região, de modo que seu estudo é essencial, tanto para abastecimento da população como para o manejo da mineração. Neste contexto, a prospecção de água subterrânea com o uso da geofísica é crescente, uma vez que a perfilagem permite estimar, in situ, propriedades petrofísicas das rochas e os fluidos que elas contêm.

Sabe-se que nas rochas sedimentares, a circulação de águas se faz através de poros e grãos. Em rochas ígneas ou metamórficas as condições aquíferas relacionam-se a zonas fraturadas (fissuradas) ou muito alteradas. A competência destas rochas não favorece tais condições de fraturamento, entretanto, quando bem desenvolvidas, as fraturas constituem uma zona preferencial para o fluxo subterrâneo. Assim, de maneira geral, as rochas se- 
dimentares devido à sua porosidade primária tendem a ser, naturalmente, bons aquíferos. No entanto, o desenvolvimento de fraturas, falhas e dissoluções pode gerar uma porosidade secundária em rochas ígneas e metamórficas originando zonas de maior capacidade de transmissão de água e assim, fazendo com que as mesmas se tornem também excelentes aquíferos.

A escolha dos métodos utilizados na perfilagem geofísica dependem do contexto geológico e, em geral, seu estudo é realizado em poços tubulares profundos para explotação de água subterrânea. Além da perfilagem, são realizados testes de bombeamento para avaliar a produtividade do poço (vazão) e determinar parâmetros hidrodinâmicos do aquífero. Este trabalho procura definir, na área de estudo, os litotipos mais favoráveis para prospecção de água subterrânea por meio de correlações entre litologia, perfilagem geofísica e vazão específica.

\section{CARACTERIZAÇÃO DA ÁREA DE ESTUDO}

A região do estudo localiza-se na porção sudoeste do Quadrilá- tero Ferrífero (QF), próxima à cidade de Congonhas (MG). O Quadrilátero Ferrífero (DORR II, 1969) é uma unidade geotectônica que aflora no sul do cráton São Francisco (ALMEIDA, 1977) e abrange uma área aproximada de $7.000 \mathrm{~km}^{2}$. Trata-se de uma região montanhosa designada como "Quadrilátero" em função da morfologia quadrangular propiciada pela disposição de sinclinais (BARBOSA, 2012). Já a designação "Ferrífero" provém da formação ferrífera bandada presente na região.

O QF já foi afetado por, pelo menos, três ciclos orogênicos: Jequié (2,7-2,5 Ga), Transamazônico (2,1-1,9 Ga) e Brasiliano (0,7-0,5 Ga) (ROSIÈRE \& CHEMALE JR, 2000). A área de estudo é um setor de grande complexidade geológica dada sua proximidade à zona de articulação entre duas estruturas regionais: Sinclinal Moeda, com traço axial aproximadamente N-S e o Sinclinal Dom Bosco, de estruturação geral E-W (Figura 1). Como reflexo estrutural é comum a presença de um grande número de falhas de empurrão e falhas transcorrentes (TRZASKOS et al., 2011).

Figura 1 - Mapa geológico simplificado do Quadrilátero Ferrífero e localização da área de estudo a sudoeste

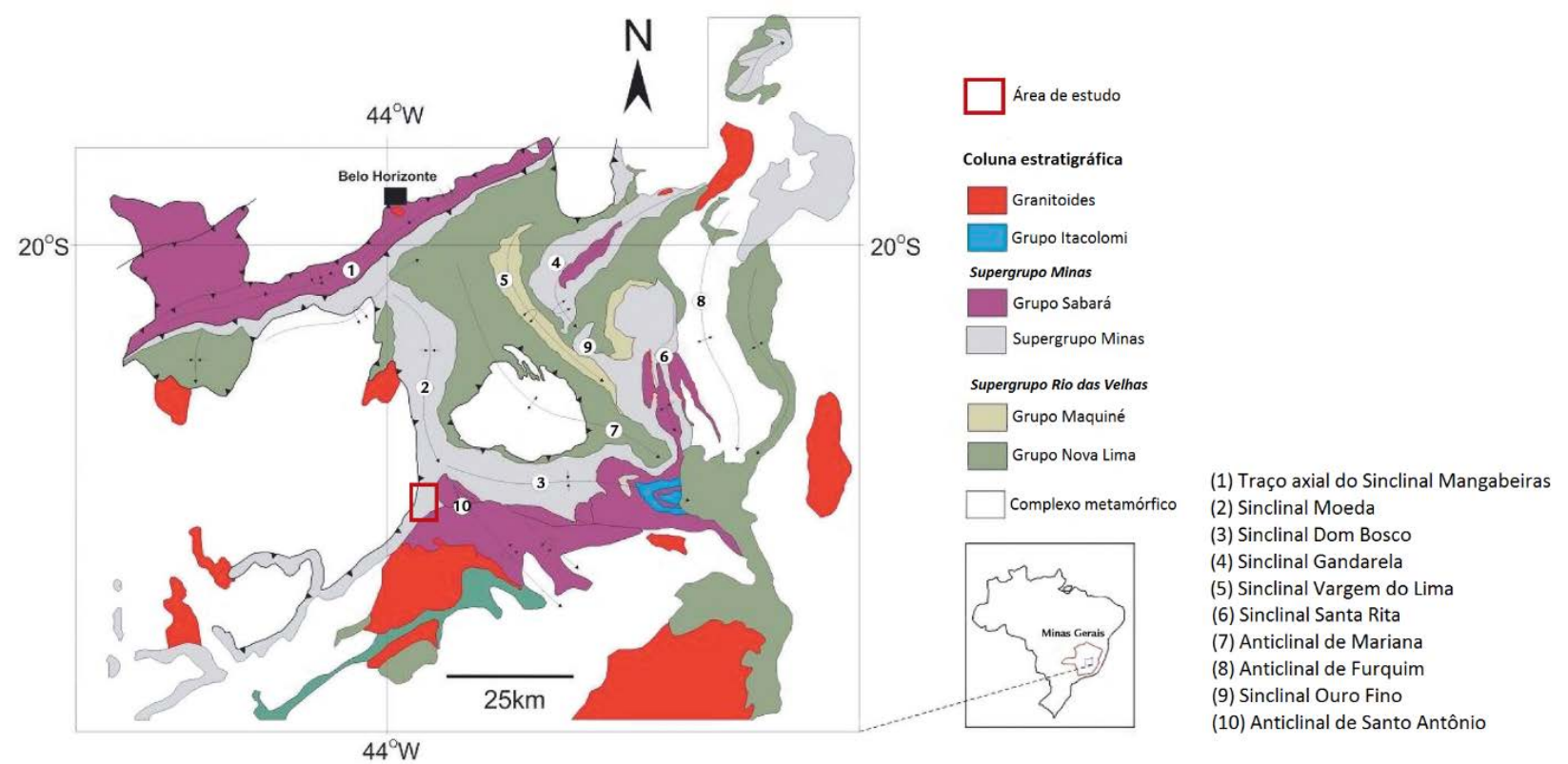

Fonte: Adaptado de Rossi \& Endo (2015)

A estratigrafia do QF é composta, da base para o topo, pelas seguintes unidades litoestratigráficas principais: terrenos granitognáissicos de idade arqueana (CARNEIRO, 1992); sequência metavulcano-sedimentar do tipo greenstone belt, que caracteriza o Supergrupo Rio das Velhas de idade arqueana (DORR II et al. 1957), e sequências metassedimentares paleoproterozóicas, que constituem o Supergrupo Minas e o Grupo Itacolomi (DORR II, 1969). Além de diques máficos intrusivos que cortam toda a sequência (ALKMIM \& MARSHAK, 1998). A coluna estratigráfica do QF pode ser vista na Figura 2.

Na área de estudo, as principais rochas aflorantes pertencem aos Grupos Piracicaba (filitos e quartzitos com pequenas intercalações de dolomito), Itabira (formação ferrífera, dolomitos e filitos) e Caraça (conglomerados, quartzitos e filitos). A Formação Cauê (Grupo Itabira) corresponde a uma sequência de rochas metassedimentares de origem fluvial a marinha plataformal de idade paleoproterozóica. Seu litotipo predominante são as formações ferríferas bandadas (BIF) que, devido a processos metamórficos e intempéricos, dividem-se em seis variedades: hematitas, itabiritos ricos, itabiritos silicosos, itabiritos goethíticos, itabiritos carbonáticos e itabiritos manganesíferos. Além disso, abriga o Aquífero Cauê, principal unidade hidrogeológica local e objeto de investigação deste trabalho. 
Figura 2 - Coluna estratigráfica do Quadrilátero Ferrífero

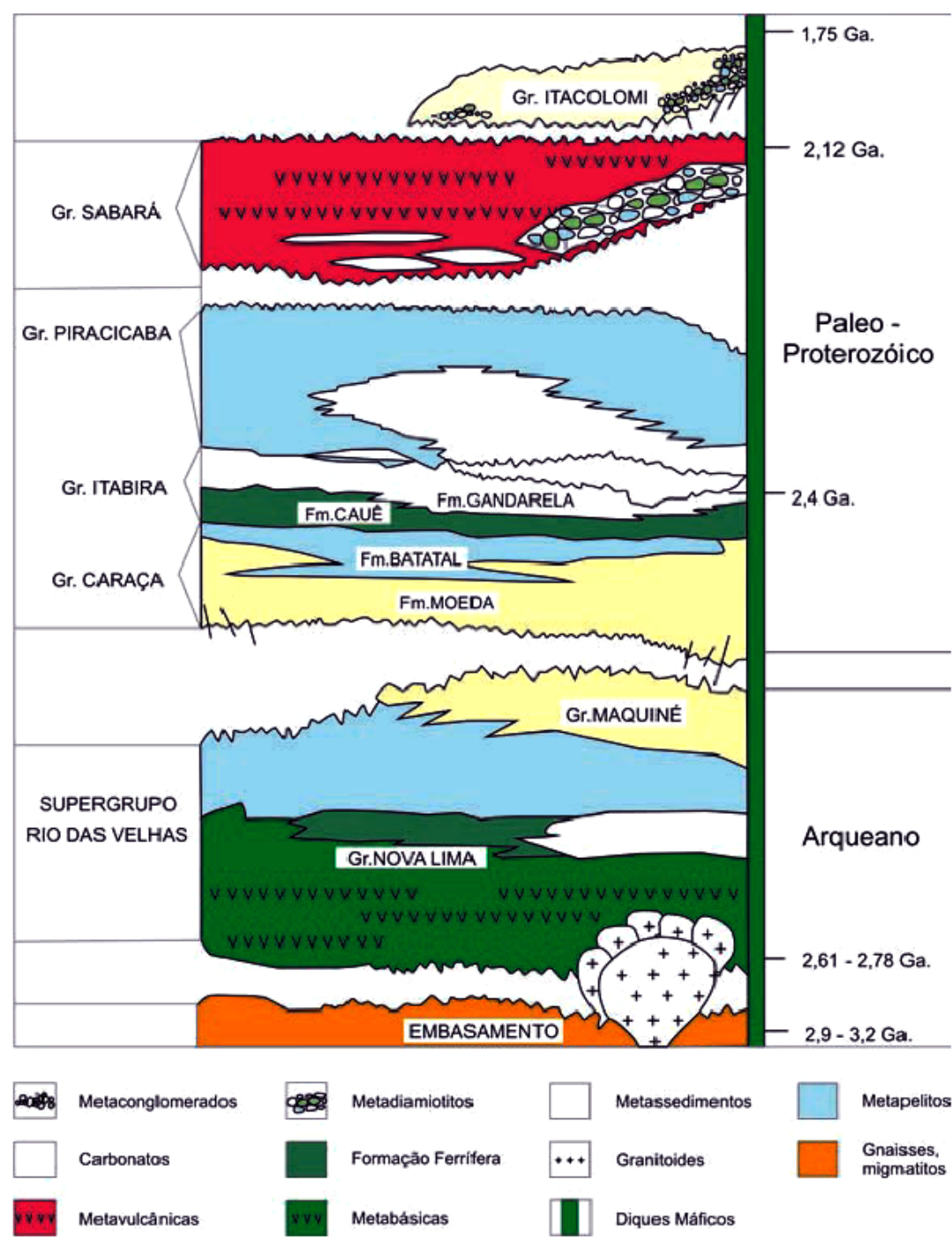

Fonte: Adaptada de Alkmim \& Marshak (1998)

O sistema aquífero do Quadrilátero Ferrífero, regionalmente, delimita-se em três grandes blocos: Homoclinal Serra do Curral, Sinclinal Moeda e Faixa Transpressiva Tamanduá-Mutuca. Sua subcompartimentação é dada por rochas de menor permeabilidade e, de acordo com suas características litológicas, os aquíferos podem ser classificados em i) inconsolidados; ii) quartzíticos; iii) carbonáticos; iv) em formações ferríferas; v) em xistos; e vi) em rochas granito-gnáissicas (MOURÃO, 2007).

A região de estudo possui um complexo sistema de aquíferos já que abrange litologias variadas. Entretanto, o Sistema Aquífero Cauê é o de maior expressividade, constituindo-se dos itabiritos e hematitas da formação homônima e possuindo zonas aquíferas associadas ao fraturamento dos dolomitos da Formação Gandarela e quartzitos da Formação Moeda (NEVES \& BERTACHINI, 2004). Já as unidades confinantes (aquitardos e aquicludes) constituem-se de filitos e metabasitos de diferentes formações, com destaque para unidade Batatal que representa o limite basal do aquífero Cauê (MOURÃO, 2007).

\section{METODOLOGIA}

A metodologia deste trabalho baseou-se na comparação de diferentes poços tubulares profundos com relação a litologia, vazão específica e perfis geofísicos.

Primeiramente, foram selecionados sete poços tubulares próximos entre si, com litologias semelhantes e vazões específicas variadas. Para uma comparação mais efetiva, foram selecionados poços compostos basicamente de hematita ou itabirito, este último variando entre itabirito silicoso, itabirito argiloso (manganesífero e goetítico) e itabirito carbonático. As vazões específicas foram obtidas a partir de testes de bombeamento. Nestes, é realizado o bombeamento do poço a uma taxa fixa, durante determinado intervalo de tempo, e medida a variação do nível de água no poço de controle e/ou em poços e piezômetros adjacentes (estruturas de observação). A partir daí obtém-se a vazão máxima do poço $\left(\mathrm{m}^{3} / \mathrm{h}\right)$ e, dividindo-a pela diferença entre nível estático e dinâmico $(m)$, chega-se a vazão específica do poço (unidade de $\mathrm{m}^{3} /$ h.m). 
Posteriormente, foram analisados os perfis geofísicos dos poços obtidos após a perfuração dos mesmos, que tiveram por objetivo promover a completação (colocação de tubos e filtros) efetiva, aproveitando ao máximo as características do aquífero para bombeamento de água. Tais perfis foram reinterpretados utilizando as ferramentas geofísicas de radioatividade natural (raios gama), potencial espontâneo (SP), resistividade e sônico, correlacionados à litologia e vazão específica de cada poço.

$O$ perfil de raios gama mede a radioatividade natural das formações, principalmente dos isótopos potássio (K), tório (Th) e urânio (U). Trata-se de uma ferramenta bastante eficaz na diferenciação entre formações argilosas e arenosas, uma vez que os elementos radioativos tendem a se concentrar em micas, argilominerais e feldspatos alcalinos. Em geral, a radioatividade em poços é medida em unidade "API" (American Petroleum Institute) (KEAREY et al., 2009). Quanto menor o gama, menor a argilosidade e, consequentemente, mais "limpa" tende a ser a formação, com os poros mais livres e, assim, maior a possibilidade de ter água.

Na ferramenta do potencial espontâneo ("self-potencial"- SP), utiliza-se um fluido de perfuração condutivo no poço para se medir a diferença de potencial, em milivolts $(\mathrm{mV})$, entre dois eletrodos, um dentro do poço e outro na superfície. Trata-se do método de prospecção elétrica mais antigo, a partir do qual é possível identificar zonas de oxirredução (FERNANDES, 1984). As maiores aplicações desta ferramenta são: detecção de camadas permeáveis, argilosidade e resistividade de água nas formações (KEAREY, 2009). No entanto, trata-se de um método nem sempre utilizado devido à dificuldade de interpretação dos seus resultados. Na hidrogeologia, pode-se dizer que valores positivos de SP indicam que a salinidade da lama de perfuração é maior que a da água da formação. Isso sugere a ocorrência de zonas de faturamento onde pode-se ter rochas mais oxidadas, infiltrações e é maior a possibilidade de água.

0 perfil de resistividade pode trabalhar com duas configurações de eletrodos que diferem quanto à profundidade de penetração na formação. O arranjo normal curto (short ou NL, 16") sofre grande influência da zona invadida pelo fluido da lama, já o normal longo (long ou NL, 64"), possibilita a investigação da zona não invadida, com menos influência da lama, medindo as características da formação e de seus fluidos originais. Na hidrogeologia, a resistividade é utilizada principalmente para detecção de feições argilosas, salinas e/ou fraturadas. Além disso, devido a sua sensibilidade quando em contato com a água, a resistividade é bastante utilizada para se inferir o nível estático em um poço.

Por fim, o perfil sônico é uma ferramenta geofísica que permite medir o tempo de trânsito de uma onda sísmica na formação e, desta forma, avaliar as velocidades sísmica nas formações e, a partir daí, pode-se estimar a sua porosidade intergranular e detectar ocasionalmente zonas de fraturas e perda de circulação (KEAREY, 2009). Seu uso para estes fins baseia-se na diferenciação da velocidade das ondas, em termos práticos, quanto maior o tempo de trânsito da onda acústica, maior a porosidade. Devese estar atento ao fato que a velocidade das ondas sísmicas é maior na matriz que nos fluidos de modo que o perfil sônico tende a registrar somente a porosidade interligada ou intergranular, não apresentando alterações em seus valores na presença de vesículas ou cavidades, porosidade secundária tipicamente encontrada em carbonatos. Seu uso para identificação de fraturas se dá apenas quando as mesmas se encontram interconectadas. Logo, altos valores do perfil sônico (ou vagarosidade) se relacionam com maior porosidade, primária ou secundária, o que pode ser favorável para a presença de água. A unidade de medição mais utilizada é ( $\mu \mathrm{ft} / \mathrm{s})$. Na hidrogeologia, o perfil sônico permite a diferenciação entre litologias brandas e compactas além da estimativa da porosidade das formações.

\section{RESULTADOS E DISCUSSÕES}

A disposição dos poços e as respectivas vazões específicas podem ser vistas na Figura 3. Os litotipos dos poços (expressos em porcentagem) podem ser vistos na Tabela 1. No texto, entretanto, serão apenas citadas as litologias de interesse com o intuito de facilitar as discussões. Analogamente, foram explicitadas apenas as porções mais significativas dos perfis geofísicos.

Tabela 1 - Litologia, profundidade e vazão específica dos poços de estudo

\begin{tabular}{|c|c|c|c|c|c|c|c|c|}
\hline & & POÇO 1 & POÇO 2 & POÇO 3 & POÇO 4 & POÇO 5 & POÇO 6 & POÇO 7 \\
\hline & Profundidade (m) & 300 & 296 & 322 & 209 & 270 & 291 & 295 \\
\hline & Vazão específica (m³/h.m) & 4,91 & 3,07 & 4,27 & 2,13 & 0,62 & 1,52 & 3,65 \\
\hline \multirow{8}{*}{ 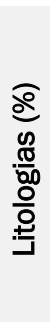 } & Hematita branda (HB) & 29 & 23 & - & - & - & 25 & 10 \\
\hline & Hematita compacta (HC) & 6 & 9 & - & - & 21 & - & - \\
\hline & Itabirito brando (IB) & 30 & 65 & 69 & - & - & - & 40 \\
\hline & Itabirito compacto (IC) & - & 3 & 28 & - & 19 & 8 & 50 \\
\hline & Itabirito argiloso brando (IAB) & 24 & - & 3 & - & - & 41 & - \\
\hline & Itabirito argiloso compacto (IAC) & - & - & - & - & - & 26 & - \\
\hline & Itabirito carbonático brando (ICB) & 11 & - & - & 58 & 60 & - & - \\
\hline & Itabirito carbonático compacto (ICC) & - & - & - & 42 & - & - & - \\
\hline
\end{tabular}


Figura 3 - Localização e vazão específica dos poços de estudo

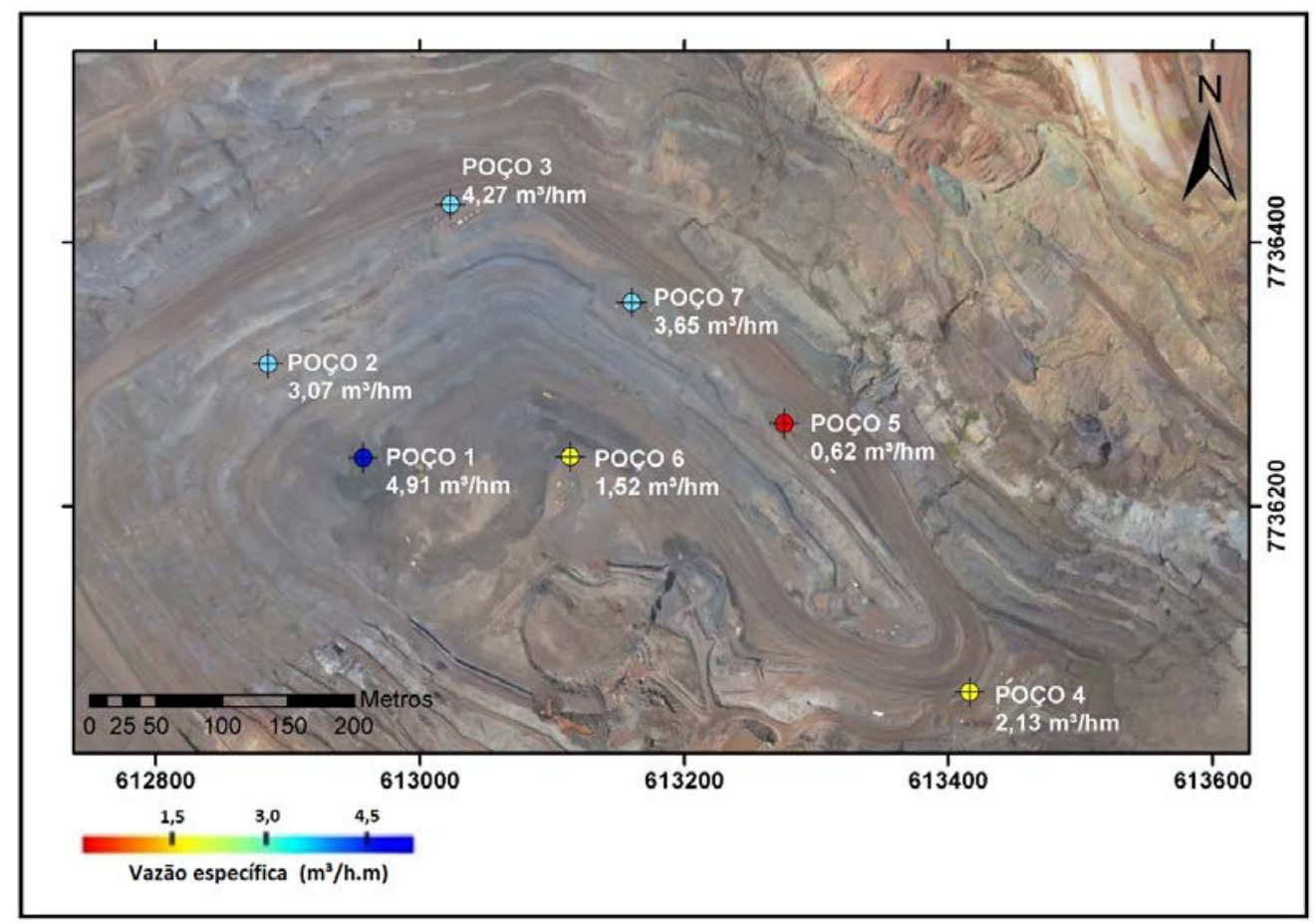

O poço 1 é composto de litologias variadas, com proporções similares entre litologias do tipo branda de hematita (29\%), itabirito (30\%) e itabirito argiloso (24\%). É um poço com uma vazão específica alta $\left(4,91 \mathrm{~m}^{3} / \mathrm{h} . \mathrm{m}\right)$, a maior dentre todos os estudados neste trabalho. 0 perfil gama natural mostra que a argilosidade fica em torno de 1500 API e diminui a partir de 185 m de profundidade, onde fica com uma média de 500 API (Figura 4). Já o perfil sônico apresenta pequenas variações até a profundidade de $200 \mathrm{~m}$, a partir da qual começa a apresentar grandes variações (de 80 a $60 \mu \mathrm{s} / \mathrm{ft}$ ), sugerindo um maior fraturamento nessa porção final do poço. Os picos estão entre 63-68 m, 170-174 m,
198-202 m, 210-215 m, 220-230 m e 260-298 m. A resistividade apresenta um comportamento relativamente uniforme (cerca de 300 e 600 ohm.m nos arranjos normal curto (NC) e normal longo (NL), respectivamente) e com alguns máximos localizados entre $50 \mathrm{~m}$ e 70-75 m e um aumento a partir de $195 \mathrm{~m}$. Esse poço não apresenta dados de SP. A elevada vazão específica desse poço deve-se, provavelmente, à porosidade e áreas de fraturamento, representados pela zona de baixa resistividade e alta vagarosidade no intervalo de hematita branda e pela porção final do poço, onde são observados baixa argilosidade e máxima vagarosidade (Figura 4).

Figura 4 - Perfil geofísico do poço 1, mostrando os intervalos mais propícios para captação de água

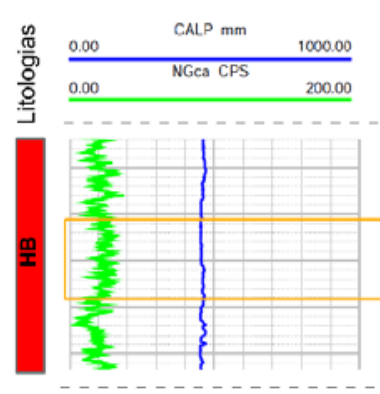

\section{POÇO 1}

\begin{tabular}{lrrrr}
0.00 & SHN OHMM & 6000.00 \\
\hline 0.00 & LONG OHMM & 6000.00 \\
\hline
\end{tabular}

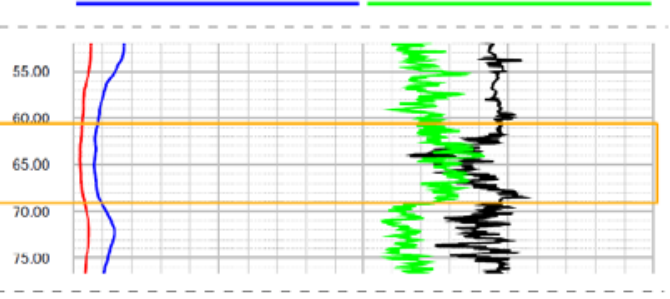

Corte do perfil geofisico
Pico do sônico, baixa
resistividade na
hematita branda
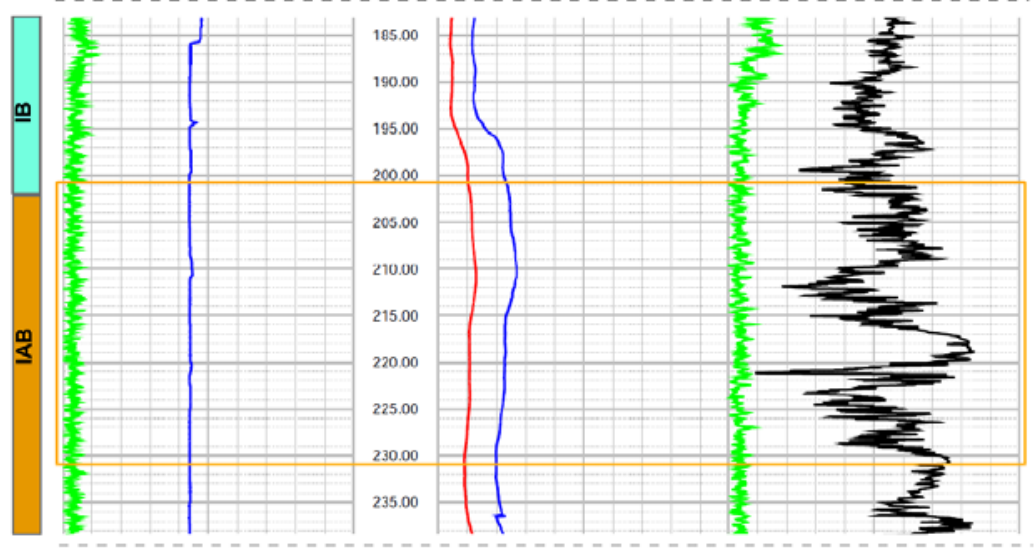

Intervalo com baixo gama e grandes picos do sônico indicando fraturamento 
0 poço 2 possui hematitas e itabiritos, onde predominam os do tipo brando (65\% itabirito brando e $23 \%$ hematita branda). Sua vazão específica é $3,07 \mathrm{~m}^{3} / \mathrm{h} . \mathrm{m}$, considerada boa para os padrões da região. No perfil de raios gama, a argilosidade é grande (em torno de $1800 \mathrm{API}$ ), com algumas oscilações até a profundidade de $182 \mathrm{~m}$, onde atinge valores mais baixos (700 API). Os valores do perfil sônico apresentam um aumento notável entre 18-25 m (picos até $1800 \mu \mathrm{s} / \mathrm{ft}$ ), no contato entre hematita branda e hematita compacta e depois se mantém praticamente constante (em torno de $140 \mu \mathrm{s} / \mathrm{ft}$ ) até a profundidade de $110 \mathrm{~m}$, a partir da qual começa a apresentar pequenas oscilações até o fim do poço. 0 perfil Caliper indica variações de diâmetro no intervalo de 16 a $26 \mathrm{~m}$. Estes dados associados indicam uma zona de fraturamento nesta região. Já os valores de resistividade apre- sentam-se homogêneos (média: NC=500 ohm.m, NL= 800 ohm.m), com algumas porções menos resistivas nos níveis de hematita e itabirito brandos. Os valores de SP, principalmente na porção dos itabiritos brandos, aumentam progressivamente (de 300 a $530 \mathrm{mV}$ ) com a profundidade do poço, ficando cada vez mais positivos, indicando rochas mais oxidadas onde a salinidade da lama é maior que a da água da formação (região mais fraturada). A análise geral da perfilagem indica que os melhores intervalos para água estão na região com ampla anomalia de vagarosidade na hematita (zona provavelmente fraturada) e em porções de baixa resistividade (possível presença de água) na hematita e itabirito brando, com destaque para profundidades abaixo de $180 \mathrm{~m}$, onde a argilosidade é mais baixa (Figura 5).

Figura 5 - Perfil geofísico do poço 2

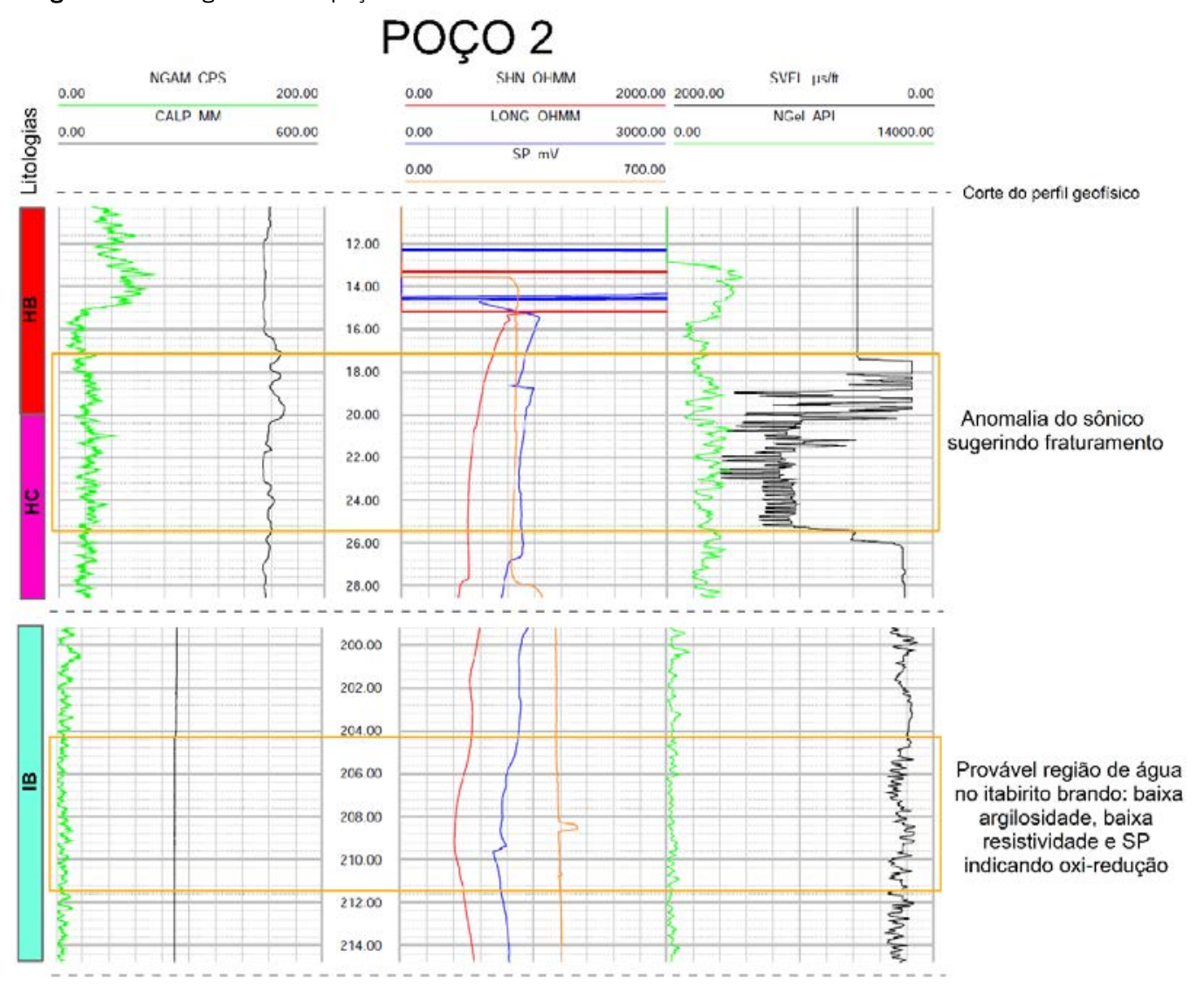

0 poço 3 apresenta como litologia predominante os itabiritos, sendo cerca de $70 \%$ de natureza branda e $30 \%$ compacta. 0 poço apresenta uma vazão específica alta $\left(4,27 \mathrm{~m}^{3} / \mathrm{h} . \mathrm{m}\right)$. Sua grande quantidade de água predomina nos itabiritos brandos e está associada à baixa argilosidade do poço (marcada pelos baixos valores de raios gama - até $10 \mathrm{API}$ - em toda a sua extensão) e ao provável fraturamento em algumas porções dos itabiritos compactos (sugeridos pelo aumento da vagarosidade - Figura 6). 0 perfil sônico apresenta variações de 100 a $300 \mu \mathrm{s} / \mathrm{ft}$ e os valores médios de resistividade são de 600 ohm.m para o NC e 1200 ohm.m para o NL). A resistividade tem alguns pontos de diminuição que coincidem com aumentos no perfil sônico, indicando possíveis fraturas preenchidas por água. O SP, por sua vez, apresenta-se positivo em todo poço, em média $350 \mathrm{mV}$. Na Figura 6 é possível notar o provável faturamento (ou porosidade secundária) nos itabiritos, principalmente na transição entre as litologias branda e compacta.

0 poço 4 é totalmente perfurado em rochas carbonáticas, com $58 \%$ de litologia branda e $42 \%$ compacta. Possui vazão específica baixa $\left(2,13 \mathrm{~m}^{3} / \mathrm{h} . \mathrm{m}\right)$, sugerindo que este tipo de itabirito não é tão favorável para água. Os valores médios dos perfis são de 15 API para os raios gama, $0 \mathrm{mV}$ no SP (inversão de valores negativos para positivos a $120 \mathrm{~m}$ de profundidade), variação de 20 a $280 \mu \mathrm{s} / \mathrm{ft}$ no perfil sônico e resistividade média de 300 ohm.m para o NC e 700 ohm.m para o NL (Figura 7). 0 perfil de raios gama apresenta baixos valores, indicando baixa argilosidade. Este fato, aliado à homogeneidade do SP, indica um maciço rochoso pouco alterado e, logo, é improvável a presença de porosidade secundária. A curva do perfil sônico apresenta-se irregular 
e serrilhada em todo poço, mas este dado sozinho não é suficiente para determinar a presença de fraturas, no entanto, quando associado as variações no diâmetro do poço (perfil Caliper), evidenciam uma zona de faturamento ou cavidades. A presença de água no poço parece estar associada a tais zonas, principalmente em locais com diminuição local da resistividade.

Figura 6 - Perfil geofísico do poço 3

\section{POÇO 3}

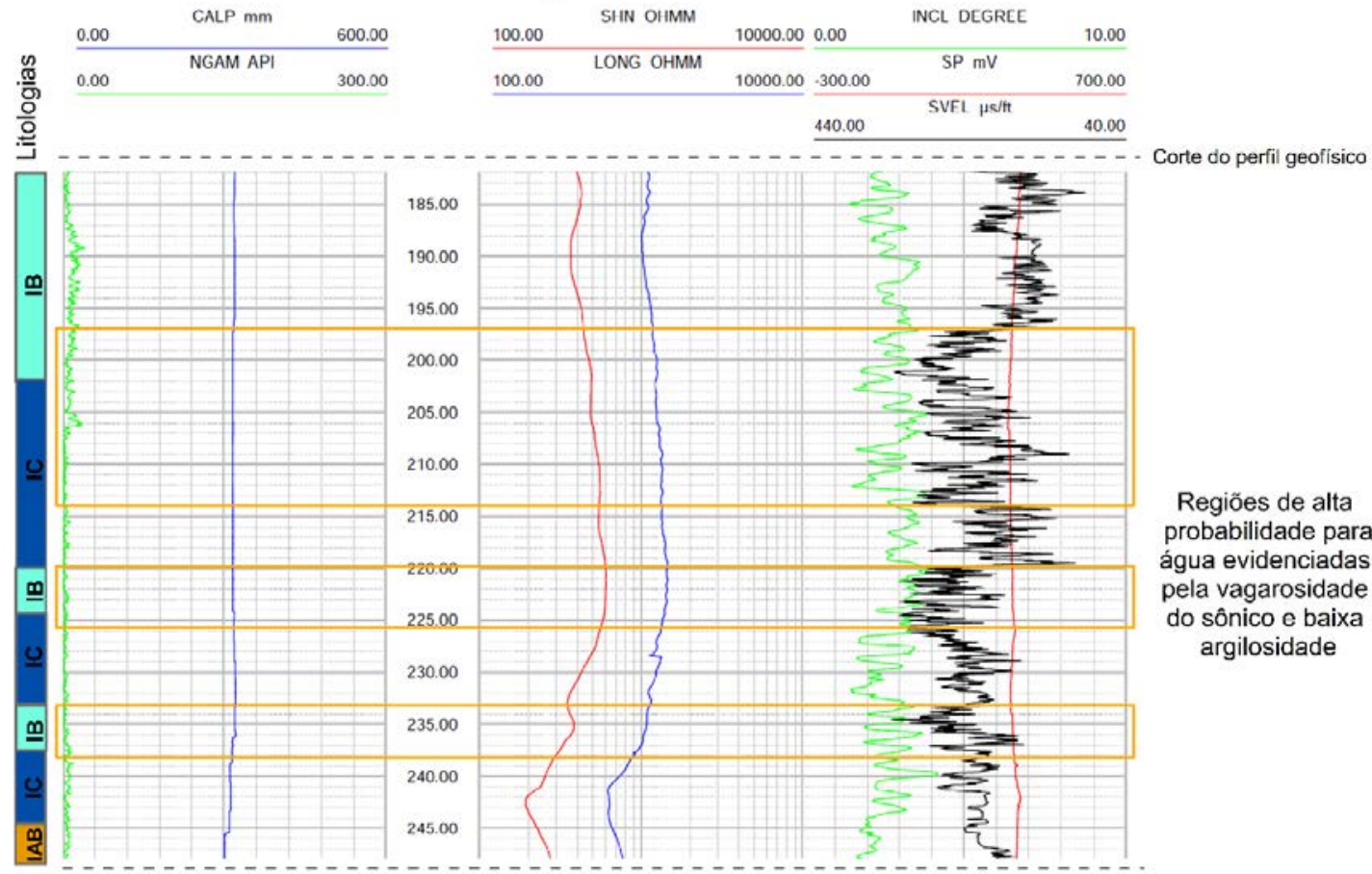

Figura 7 - Perfil geofísico do poço 4

\section{POÇO 4}

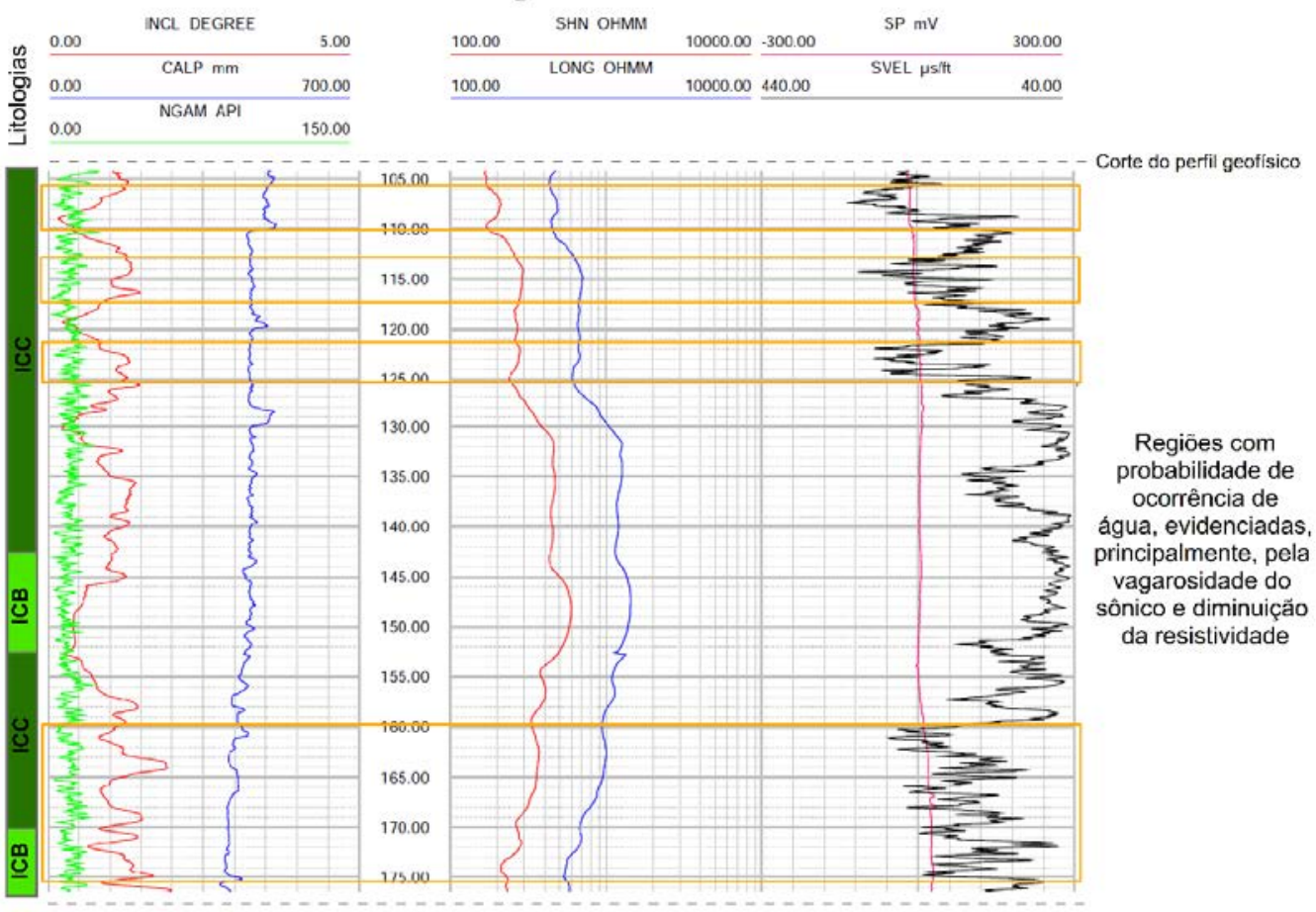


A análise do poço 5 abrange duas litologias compactas (hematita e itabirito) e uma litologia carbonática branda que é predominante (60\%). O perfil de raios gama natural mostra picos significativos até a profundidade de $78 \mathrm{~m}$ (intervalo onde estão as litologias compactas) e depois se mantém em torno de 15 API (Figura 8). É interessante notar que um dos maiores picos se dá próximo ao contato entre a hematita compacta e o itabirito compacto (Figura 8). Os valores de vagarosidade, por sua vez, mostram-se mais homogêneos (cerca de $200 \mu \mathrm{s} / \mathrm{ft}$ ) nessa primeira porção do poço e a partir dos $105 \mathrm{~m}$ de profundidade, próximo ao contato do itabirito compacto com o carbonático, inicia seu comportamento irregular e serrilhado (variação de 10 a 320 $\mu \mathrm{s} / \mathrm{ft}$ ). Já a resistividade apresenta valores mais baixos nas litologias compactas embora exista uma redução de valor no itabirito dolomítico brando no intervalo entre $145-180 \mathrm{~m}$. No geral, a resistividade no Normal Curto varia entre $100-600$ ohm.m e no Normal Longo de 300-1200 ohm.m). O SP apresenta-se positivo em todo poço, aumentando progressivamente com a profundidade e com uma média de $90 \mathrm{mV}$. 0 poço 5 apresenta vazão específica baixa, a menor entre os poços deste estudo: 0,63 $\mathrm{m}^{3} / \mathrm{h} . \mathrm{m}$. Embora alguns intervalos do poço apresentem um conjunto de respostas que poderiam ser positivas para água (baixa argilosidade, baixa resistividade e alta vagarosidade), o perfil SP mantém um comportamento bem estável, sugerindo pouca permeabilidade das camadas. Assim, a baixa vazão específica desse poço pode ser devido à menor quantidade de água na litologia carbonática quando comparada às hematitas e itabiritos. Além disso, o intervalo de hematita, que poderia ser favorável para água, é compacto, sem nenhum indício de fraturamento, seco e com altos valores de raios gama.

Figura 8 - Perfil geofísico do poço 5

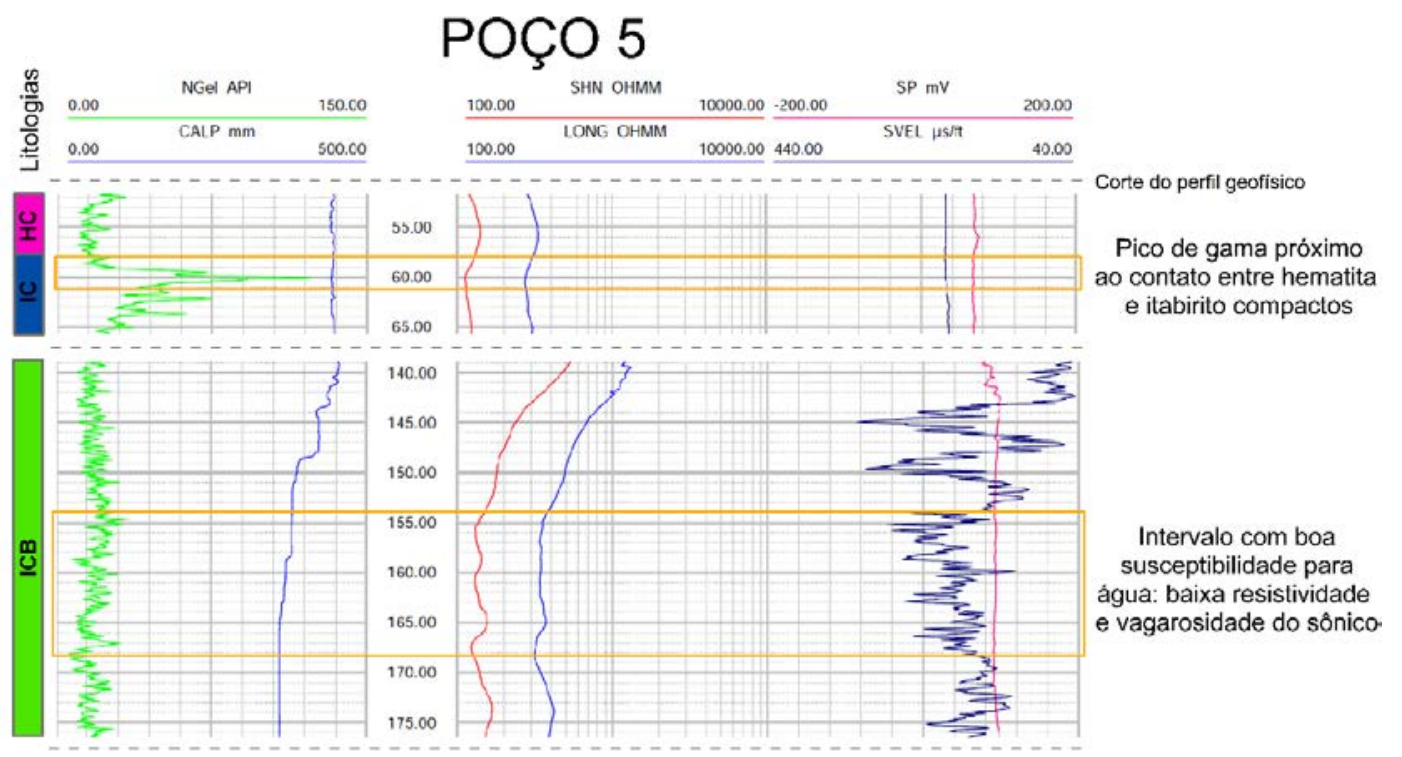

0 poço 6 possui litologias variadas com predomínio das do tipo argiloso (67\%) e vazão específica baixa (1,52 m³/h.m). 0 perfil gama apresenta valores mais elevados do que nos outros poços. Analogamente ao perfil de raios gama, os valores do perfil sônico possuem uma extensa variação ( 0 a $450 \mu \mathrm{s} / \mathrm{ft}$ ). A resistividade mostra valores mais baixos (média: $\mathrm{NC}=750$ ohm.m, $\mathrm{NL}=1600$ ohm.m) principalmente nas porções mais superficiais do poço (até $105 \mathrm{~m}$ ). Já a ferramenta SP possui valores negativos (-1100 a $-600 \mathrm{mV}$ ) em todo o poço, exceto por alguns picos muito positivos (111 m, 259 m, 264 m e 283 m). São áreas de rochas mais oxidadas nas quais a salinidade da lama é maior que a da água da formação. Tratam-se de regiões possivelmente mais fraturadas e com maior potencial para água (Figura 9). Apesar destas áreas potenciais, a baixa vazão específica do poço provavelmente relaciona-se à predominância de litologia argilosa. 
Figura 9 - Perfil geofísico do poço 6

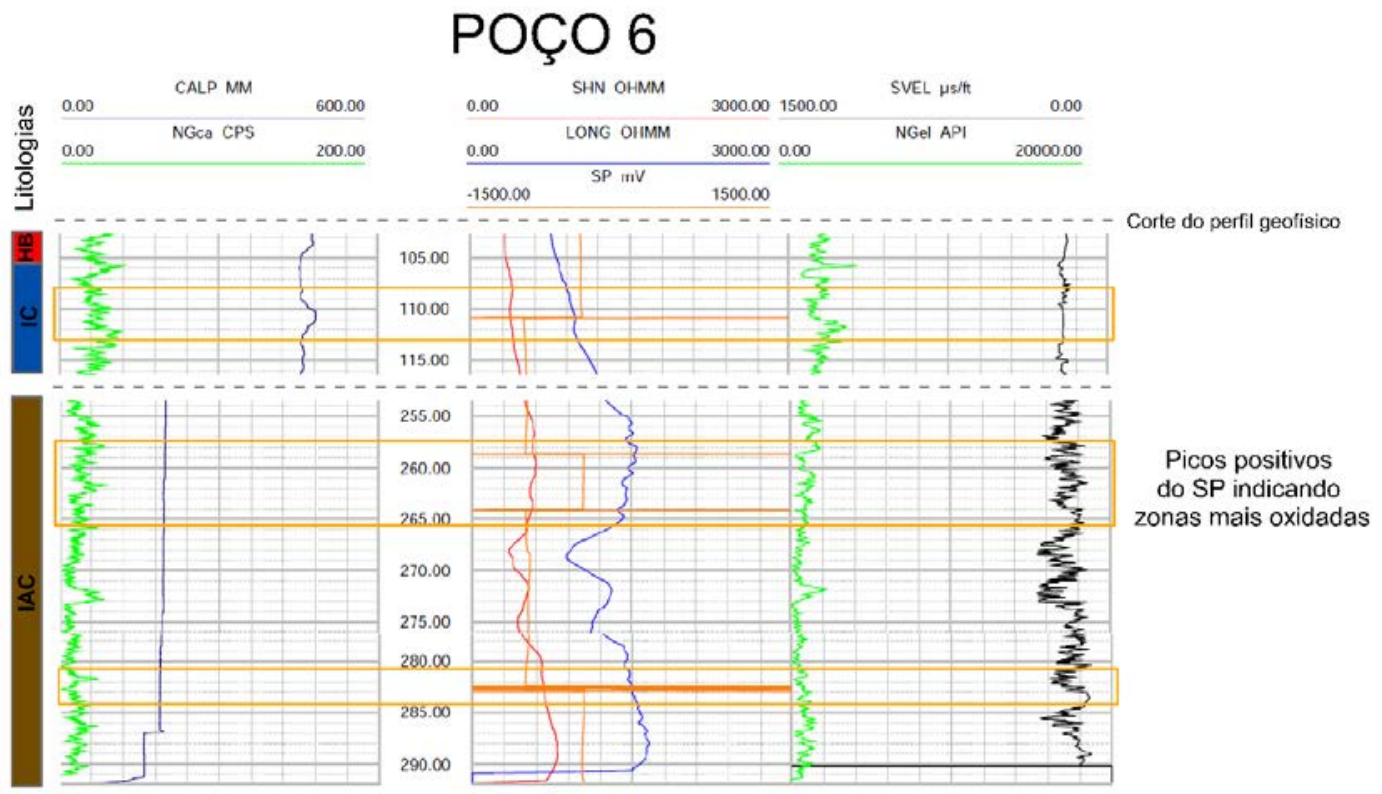

O poço 7 apresenta composição também predominantemente de itabiritos, entretanto, ao contrário do poço 3, aqui predominam os itabiritos compactos (50\%) em detrimento dos brandos (40\%). Sua vazão específica $\left(3,68 \mathrm{~m}^{3} / \mathrm{h} . \mathrm{m}\right)$ é menor que a do poço anterior (poço 6) mas ainda continua sendo um valor alto. Os intervalos litológicos deste poço são menores e, por isso, tem-se uma maior variação entre litologias. Os valores de raios gama diminuem a partir da profundidade de $177 \mathrm{~m}(<500 \mathrm{API})$ e o perfil sônico apresenta variações (100-320 $\mu \mathrm{s} / \mathrm{ft}$ ) a partir de $75 \mathrm{~m}$. 0 $\mathrm{SP}$ (variação de -100 a $100 \mathrm{mV}$ ) aumenta progressivamente com a profundidade, passando de negativo para positivo em $180 \mathrm{~m}$, indicando que, a partir deste ponto, a salinidade da lama é maior que a da água da formação, o que pode ser indício de áreas fraturadas. Já a resistividade varia muito (NC= 200-600 ohm.m, $\mathrm{NL}=500-1500 \mathrm{ohm} . \mathrm{m}$ ), mas possui dois baixos nas profundidades de 207 e 235 m, que parecem estar associados ao contato entre itabirito brando e compacto. Acredita-se que a grande transição entre litologias no poço seja favorável a zonas de fraturamento, e, consequentemente, ao acúmulo de água.

Figura 10 - Perfil geofísico do poço 7

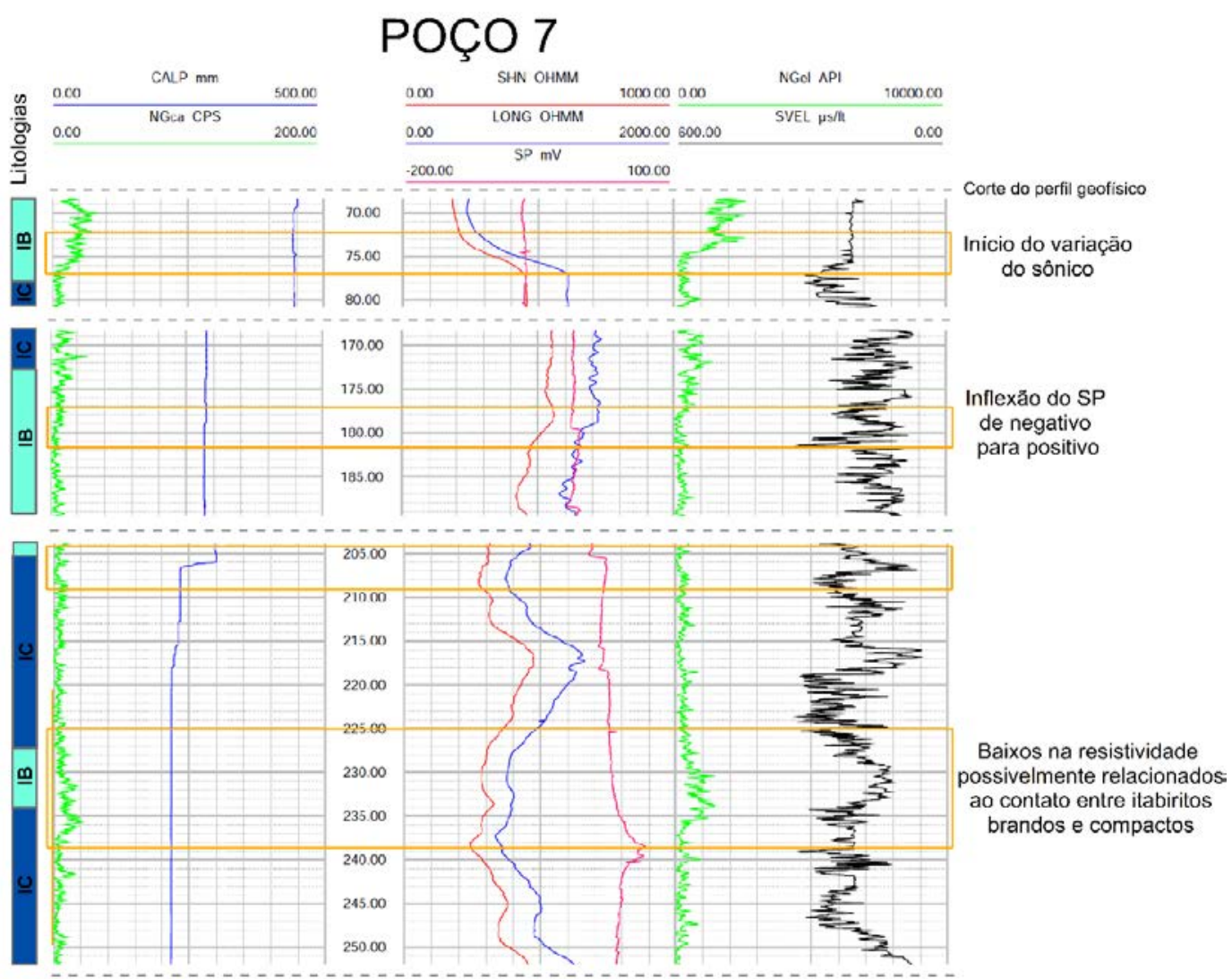




\section{CONCLUSÕES}

Com base na interpretação dos dados, nota-se que, na área de estudo, a litologia mais favorável para presença de água são as hematitas brandas, como evidenciado pelos poços 1 e 2 (poço 1 : v.e. $4,91 \mathrm{~m}^{3} / \mathrm{h} . \mathrm{m}$ e $35 \%$ de hematita) (poço 2: v.e. $3,07 \mathrm{~m}^{3} / \mathrm{h} . \mathrm{m}$, $31 \%$ de hematita), seguidas pelos itabiritos brandos. Isso ocorre porque as hematitas são lixiviadas em sílica em relação aos itabiritos e o raio atômico do ferro (Fe) é maior que o do silício ( $\mathrm{Si}$ ). Assim, as hematitas possuem um arranjo atômico com maior distância interatômica, aumentando o espaço intersticial nessas rochas e, consequentemente, sua porosidade.

A comparação entre os poços 3 e 7 , de composição predominante de itabiritos brandos (IB) e compactos (IC) permite inferir que os itabiritos brandos são mais propícios para água (poço 3: v.e. $4,3 \mathrm{~m}^{3} / \mathrm{h} . \mathrm{m} \mathrm{e} 72 \%$ IB e $26 \%$ IC) (poço 7 : v.e. $3,7 \mathrm{~m}^{3} / \mathrm{h} . \mathrm{m}, 40 \%$ IB e $50 \%$ IC). Nesse caso, as litologias brandas sofreram um grau de metamorfismo menor que as litologias compactas, que se encontram em profundidade maior. Assim, as rochas compactas são mais competentes e, portanto, tendem a ser mais resistentes que as brandas com relação a geração de porosidade secundária (fraturamento e intemperismo).

A análise da perfilagem mostra ainda que os trechos de transição entre litologias e porções de itabirito compacto fraturadas são também intervalos com grande potencial para água. Este fraturamento pode ser indicado com o auxílio do perfil sônico (grande variação e altos valores) e a presença de água pode ser interpretada com uma diminuição da resistividade nesses locais. Este comportamento se dá pela água subterrânea procurar estruturas como falhas, fraturas e contatos litológicos para direcionamento do fluxo de água.

É importante ressaltar que a análise das ferramentas geofísicas deve ser sempre realizada em conjunto. No entanto, a análise individual das respostas de raios gama parece ser bem eficaz com relação ao potencial para água. A título de exemplo podem ser citados os poços 3 e 6 que possuem baixa e elevada argilosidade, respectivamente, e vazões específicas proporcionais a tais valores (poço 3: v.e. 4,3 $\mathrm{m}^{3} / \mathrm{h}$.m e $14 \%$ de itabirito argiloso) (poço 6: v.e.1,52 $\mathrm{m}^{3} / \mathrm{h} . \mathrm{m} \mathrm{e} 67 \%$ de itabirito argiloso).

Por fim, itabiritos carbonáticos parecem não ser tão favoráveis para água como mostra o poço 5 (poço 5: v.e.0,63 m³/h.m e 60\% de itabirito carbonático). No entanto, quando o maciço rochoso carbonático encontra-se fraturado ou com dissoluções (porosidade secundária) a favorabilidade para água aumenta, como visto na análise do poço 4 (poço 4: v.e.2,13 m³/h.m e 100\% de itabirito carbonático).

\section{REFERÊNCIAS}

ALKMIM F.F. \& MARSHAK S. Transamazonian orogeny in the southern São Francisco craton, Minas Gerais, Brazil: evidence for paleoproterozoic collision and collapse in the quadrilátero ferrífero. Precambrian Research, v. 90, n. 1, p. :29-58, 1998.

ALMEIDA, F.F.M. O Cráton do São Francisco. Revista Bras. Geociências 7, 349-364, 1977.
BARBOSA P.F. Investigação dos processos formadores de bandamento composicional em formações ferríferas do Quadrilátero Ferrífero. Dissertação (Mestrado) -Universidade Federal de Ouro Preto, Ouro Preto, 2012. $181 \mathrm{p}$.

CARNEIRO, M. A. O complexo metamórfico Bonfim Setentrional (Quadrilátero Ferrífero, Minas Gerais): litoestratigrafia e evolução geológica de um segmento de crosta continental do Arqueano. Tese (Doutorado) - Universidade de São Paulo. São Paulo, 1992.

CHEMALE, F. JR., QUADE, H. \& SANTANA, F. C. 1987. Economic and structural geology of the Itabira Iron District, Minas Gerais, Brazil. Zbl. Geol. Paläontol., v. 6, n. 7/8, p. 743 - 752, 1987.

DORR II, J. V. N. Physiographic, stratigraphic and structural development of the Quadrilátero Ferrífero, Brazil. United States Geological Survey Professional Paper 641-A., 1969. $110 \mathrm{p}$.

DORR II, J.V., GAIR, J.E., POMERENE, J.B., RYNEARSON, G.A. Revisão da estratigrafia pré-cambriana do Quadrilátero Ferrífero, Brasil. Departamento Nacional da Produção Mineral, Divisão de Fomento da Produção Mineral DNPM-DFPM. [S.I.], avulso, v. 81, 1957. 31p.

ENDO I. Regimes tectônicos do Arqueano e Proterozóico no interior da placa Sanfranciscana: Quadrilátero Ferrífero e áreas adjacentes, Minas Gerais. Tese de Doutoramento, Instituto de Geociências, Universidade de São Paulo, 1997. 328p.

ELIS, V. R. Prospecção de águas subterrâneas com o uso de métodos geofísicos. Grupo de Pesquisa em Geofísica Aplicada. Universidade de São Paulo. Disponível em: http://www.iag.usp.br/agua/geo/prospec_vagner.pdf. Acesso em: 17 abr. 2017.

FERNANDES, C.E.de M. Fundamentos de prospecção geofísica. Rio de Janeiro: Interciência, 1984. 190p.

KEAREY P., BROOKS M., HILL I. Geofísica de exploração. São Paulo: Oficina de Textos, 2009. $438 \mathrm{p}$.

MOURÃO, M. A. Caracterização hidrogeológica do Aquífero Cauê, Quadrilátero Ferrífero, MG. Tese (Doutorado)- Universidade Federal de Minas Gerais. Belo Horizonte, 2007. 297p.

NEVES, ANA C.; BERTACHINI, ANTÔNIO C. Modelo hidrogeológico conceitual e matemático, mineração Casa de Pedra, Congonhas - MG. In: CONGRESSO BRASILEIO DE GEOLOGIA., 42, 2004. Araxá. Anais... Belo Horizonte: SBG-MG, 2004. 1 CD-ROM.

ROSIĖRE C.A. \& CHEMALE F. Brazilian iron formations and their geological setting. Revista Brasileira de Geociências, v. 30, p. 274-278, 2000.

ROSIÈRE, C. A.. Strukturelle und texturelle Untersuchungen in der Eisenerzlagerstätte "Pico de Itabira" bei Itabirito/Minas Gerais, Brasilien. Clausthaler Geowissenschaftliche Dissertationen, 9: 302pp, ClausthalZellerfeld, 1981.

ROSIĖRE C.A. A recristalização do minério de ferro da jazida o Pico de Itabirito no Quadrilátero Ferrífero, MG e sua implicações genéticas. In: SBG, Simpósio de Geologia de Minas Gerais, 2,. 1992. Anais... p. 173186, 1992.

ROSIĖRE C.A., CHEMALE JR. F., GUIMARÃES M.L.V. Um modelo para a evolução microestrutural dos minérios de ferro do Quadrilátero Ferrífero. Parte I - Estruturas e Recristalização. Geonomos, v. 1, n. 1, p. 65-84, 1995.

ROSSI, D. Q. \& ENDO, I. A structural model of the Fábrica Nova region, Santa Rita syncline, Quadrilátero Ferrífero: flanking folds as a folding mechanism. Revista Escola de Minas, Ouro Preto, v. 68, n. 2, p. 153-162, 2015.

TRZASKOS, B.; ALKMIM, F.F.; ZAVAGLIA, G. 2011. Arcabouço estrutural e microestruturas do minério de ferro da jazida de Casa de Pedra, Quadrilátero Ferrífero, MG. Revista Brasileira de Geociências, v. 41, p. 486-497. 
ZAVAGLIA, G. Condicionantes Geológicos do Comportamento dos Minérios de Ferro do Depósito de Tamanduá (MG) no processo metalúrgico de redução direta. 1995. 200 f. Dissertação (Mestrado em Geologia) - Departamento de Geologia, Universidade Federal de Ouro Preto, Ouro Preto, 1995.
ZUCCHETTI M. \& BALTAZAR O.F. Rio das Velhas Greenstone Belt lithofacies associations, Quadrilátero Ferrífero, Minas Gerais, Brazil. In: 31th International Geological Congress. Anais... Rio de Janeiro, 2000. CD-ROM 